\title{
Sistem Informasi Warehouse Dengan Model Rapid Aplication Development (Studi Kasus PT. Serambi Gayo Sentosa)
}

\author{
Ishak kholil $^{1}$, Instianti Elyana ${ }^{2}$, Tulus Yoshua ${ }^{3}$ \\ ${ }^{1}$ STMIK Nusa Mandiri \\ Jl. Damai No 8 Warung Jati Barat( Marga Satwa) Jakarta Selatan \\ Telp. (021) 78839513. Mobile : 087883902449 \\ Website : www.nusamandiri.ac.id Email : ishak.ihk@nusamandiri.ac.id \\ ${ }^{2 \& 3}$ Universitas Bina Sarana Informatika \\ Jl. Kamal Raya No.8 Ringroad Barat Cengkareng Jakarta Barat \\ Telp : (021)8000063. Mobile : 081314346155 \\ Website : www.bsi.ac.id Email :instianti.iny@bsi.ac.id
}

\begin{abstract}
Abstrak - Perkembangan teknologi informasi saat ini sangat pesat. Tentu hal ini harus ditanggapi dengan serius oleh dunia usaha, tentunya untuk kepentingan kemajuan perusahaan. Pengelolaan data menjadi bidang yang sangat membutuhkan support tool dari sebuah sistem informasi, yaitu untuk menghasilkan data yang valid. PT Serambi Gayo Sentosa sebagai perusahaan bidang jasa kelistrikan sangat membutuhkan sistem tersebut dimana saat ini perusahaan tersebut masih mengunakan sistem yang manual untuk pengolahan datanya. Dengan sistem manual sering ditemukan kesalahan dala perhitungan dan pencarian data. Dari permasalahan tersebut penulis mengusulkan sistem informasi warehouse yang mencakup fungsi pencatatan, penyimpanan, pengolahan serta laporan barang untuk memudahkan bagian gudang dalam pengolahan data. Mengunakan model rapid aplication development dalam pembagunan aplikasinya. Pengujian compatibility sistem berjalan baik di internet explorer dan Mozzila Firefox serta penggujian white-box dan black-box testing. Hasil pengujian menunjukan bahwa sistem berhasil dianalisis kebutuhannya serta terimplementasikan sesuai dengan perancangan. Dan dapat mengatasi permasalahan sistem yang masih manual pada perusahaan.
\end{abstract}

Kata kunci: Warehouse, Sistem Informasi, jasa kelistrikan.

\section{Pendahuluan}

Era revolusi industri.4.0 saat ini sudah menjadi perhatian serius bagi dunia usaha, baik yang bergerak dibidang manufaktur maupun jasa. Revolusi industri 4.0 ditandai dengan pesatnya perkembangan teknologi informasi, tentu hal ini menjadi permasalahan bagi dunia usaha, yaitu bagaimana cara untuk mengelola data sehingga menghasilkan informasi untuk end user disetiap lini organisasi. Banyak dunia usaha yang saat ini belum secara keseluruhan menerapkan teknologi informasi dalam pekejaannya.

Selain penerapan teknologi, permasalahan lain yang dihadapi dunia usaha adalah kesiapan sumber daya manusia (SDM). Manusia sebagai penguna/end user harus mampu beradab tasi dengan teknologi sesuai perkembangannya. Adabtasi yang dilakukan tentu dengan jalur pendidikan, melalui pendidikan manusia dipersiapkan menjadi sumber daya yang unggul dan kompeten sesuai dengan bidang pendidikan yang ditekuninya.

PT. Serambi Gayo Sentosa adalah perusahaan menyediakan pelayanan barang dan jasa yang bergerak dibidang kelistrikan yang berdomisili di jalan Raya Cimuning Kota Bekasi. PT. Serambi Gayo Sentosa didirikan pada tanggal 25 Februari 2008 yang merupakan pengembangan usaha dari CV. Serambi gayo yang berdiri Tahun 2006. PT. Serambi Gayo Sentosa merupakan perusahaan rekanan PLN (Perusahaan Listrik Negara) diwilayah Jawa Barat dan Banten. Hal ini dikarenakan komitmennya terhadap kualitas produk yang pasarkan serta pelayanannya terhadap konsumen sangat menjadi perhatian perusahaan. Dalam meningkatkan pelayanan PT. Serambi Gayo Sentosa ini telah memiliki beberapa cabang yang 
tersebar dibeberapa daerah dijawa barat dan banten dengan tujuan agar lebih dekat terhadap konsumen.

PT Serambi Gayo Sentosa memiliki struktur organisasi yang terdiri dari bagian produksi, gudang, purchasing, quality control dan bagian lainnya. Sebagai perusahaan dibidang penyedia barang PT Serambi Gayo Sentosa rutin dengan kegiatan pengawasan, pencatatan terhadap data barang, serta pengelolaan data barang yang tersedia digudang. Pencatatan masih dilakukan

dengan menggunakan aplikasi microsoft excel. Perlunya dengan di bangun aplikasi sistem informasi warehouse berbasis web diharapkan dapat memberi solusi untuk efektifitas organisasi. Memudahkan penguna dalam melakukan pengontrolan stok barang.

\section{$2 \quad$ Landasan Teori}

Sistem informasi berguna sebagai tool dalam mengelola data dan memiliki peran penting bagi sebuah organisasi/perusahaan, sebuah sistem informasi dapat digunakan untuk mengelola data dengan jumlah yang banyak , apalagi disebuah organisasi/perusahaan besar pasti membutuhkan tool sebagai alat bantu untuk perhitungan dan penyampaian data yang tinggi. aplikasi berbasis web sangat tepat untuk efektifitas dan produktifitas, serta efisiensi dalam organisasi . Pada penelitian yang berjudul sistem informasi warehouse bebasis internet dengan studii kasus pada PT Duta Mas Satu, Pencatatan inventory produk pada suatu perusahaan merupakan salah satu pendukung utama dalam proses pendistribusian barang [1].

Dipenelitian dengan judul perancangan dan implementasi warehouse management system di PT Pertamina DPPU Ngurah Rai menunjukkan bahwa sistem ini sudah beroperasi sesuai yaitu dapat mempercepat lead time proses karena proses yang terjadi seperti pencatatan data barang, pencatatan data transaksi, penghitungan jumlah barang, serta pencetakan laporan dilakukan secara komputerisasi ([2].

Oleh karena itu dibutuhkan pemanfaatan sistem informasi untuk mendukung proses pencatatan dan pengelolaan data gudang untuk mempercepat pelaporan dan pencarian data. Karena itu diperlukan sebuah aplikasi warehouse untuk memudahkan dalam sistem pengelolaan data barang digudang pada sebuah organisasi. Kebutuhan perusahan yaitu dengan membuat perangkat lunak untuk workflow pengelolaan data gudang lebih khususnya pada bagian gudang.

Pengembangan aplikasi tentu harus didukung oleh metode yang tepat, Unified modeling Language (UML) banyak penelitian terdahulu yang mengunakan [3],[4], [5].

Penelitian ini bertujuan, membangun sebuah sistem informasi warehouse yang diharapkan dapat membantu staf gudang dalam menyelesaikan tugas, penerimaan barang, penyimpanan barang, dan pengambilan barang. Hal ini merupakan tujuan dari sebuah otomastisasi alat dalam mengolahan data untuk menghasilkan informasi yang akurat dan efektif untuk target keuntungan perusahaan.
Rapid Application Development (RAD), metodologi yang banyak digunakan untuk membuat sebuah prototype dengan sampel kasus yang bervariasi dan banyak mengunakan aplikasi berbasis website. Metode ini sudah banyak diterapkan dibanyak jurnal penelitian yang penulis mencoba mengunakan sebagai referensi. [6],[7],[8],[9]

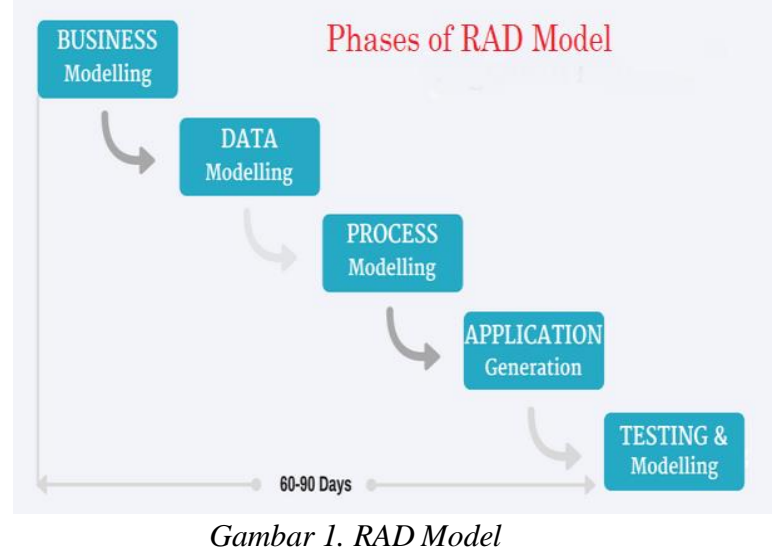

\subsection{Bisnis Model}

Aliran informasi antar fungsi bisnis dimodelkan dalam cara memahami banyak hal tentang hal berikut: Informasi yang mendorong bisnis proses apa? Informasi yang dihasilkan apa? Siapa yang menghasilkan dan memprosesnya? Kemana perginya informasi?

\subsection{Data Model}

Aliran informasi didefinisikan sebagai bagian dari urutan model bisnis yang disempurnakan menjadi satu set objek data yang diperlukan untuk mendukung bisnis atau disebut atribut dari setiap objek diidentifikasi dan didefinisikan

\subsection{Proses Model}

Objek data yang diterjemahkan dengan urutan pemodelan data ditransformasikan demi pencapaian aliran informasi yang diperlukan sebagai implementasi fungsi proses bisnis. Memproses deskripsi dibuat proses CRUD (Create, Read, Update, Delete) objek data.

\subsection{Application Generation.}

RAD sering digunakan dengan mengunakan penggunaan teknik generasi keempat. Hal ini tentu lebih baik dari sofware generasi ketiga. bahasa pemrogramanyang digunakan proses RAD Dalam banyak hal, otomatissasi alat digunakan untuk pembangunan perangkat lunak.

\subsection{Testing Model}

Proses RAD banyak membahas tentang penggunaan kembali komponen-komponen program yang telah diuji. Hal ini bertujuan untuk mengurangi waktu pengujian secara keseluruhan. Namun, komponen baru harus diuji dan semua antarmuka harus dilakukan sepenuhnya.

\section{Perancangan Sistem}

Pada sistem yang penulis bahas ini, PT. Serambi Gayo Sentosa dengan Business Model sebagai berikut: 


\subsection{Pemesanan Barang}

Pada proses ini dalam melakukan pesanan bagian Adm Logistik membuka Data barang untuk melihat barang apa saja yang ingin dipesan. Dalam melakukan pesanan Adm Logistik membuat permintaan barang ke supplier melalui via email dan dikirimkan ke supplier untuk diproses. Setelah permintaan barang diproses kemudian supplier mengirimkan barang sesuai pesanan dengan dilengkapi dokumen berupa Purchase Order. Bagian Adm Logistik melakukan pengecekan barang yang dipesan beserta dokumennya dan diinput kedalam data barang. Purchase order diarsip kedalam arsip barang masuk, dan permintaan barang via email akan diarsip kedalam permintaan barang.

\subsection{Pengeluaran Barang}

Dalam proses ini bagian Staff membuat Daftar Permintaan Barang sesuai dengan permintaan. Daftar Permintaan Barang yang telah dibuat oleh bagian Staff diberikan kepada bagian Adm Logistik untuk dicek dengan melihat persediaan barang pada data barang dan disiapkan untuk dikasih ke staff. Daftar Permintaan Barang yang telah disetujui oleh Adm Logistik kemudian dikembalikan kepada bagian Staff untuk diarsipkan kedalam data barang keluar.

\subsection{Pendataan Stock Barang}

Seluruh barang masuk dan barang yang keluar yang telah di data oleh bagian Adm Logistik kedalam data barang sesuai dengan kode barang, nama barang dan jumlah barang yang ada digudang.

\subsection{Laporan}

Dan pada proses ini seluruh file data barang, file barang masuk dan file barang keluar dibuat laporan oleh bagian Adm Logistik dan diserahkan kebagian Spv Gudang untuk diperiksa dan Adm Logistik menyimpan data laporan.

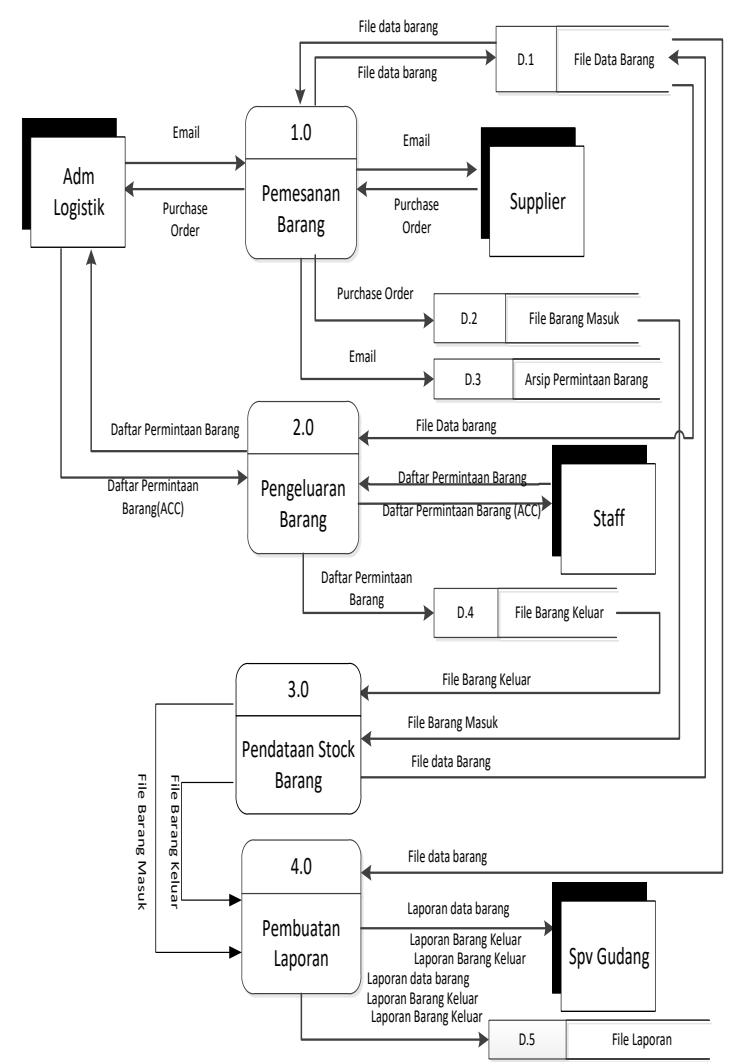

Gambar. 2. Data flow Diagram

\subsection{ERD (Entity Relationship Diagram)}

Model ini dibuat untuk menjelaskan hubungan antar relasi data dalam basis data berdasarkan objek-objek dasar data yang mempunyai hubungan relasi. Dari hasil pengamatan pengelolaan data gudang suatu di sebuah perusahaan dibuat lah ERD dengan penggambaran sebagai berikut :

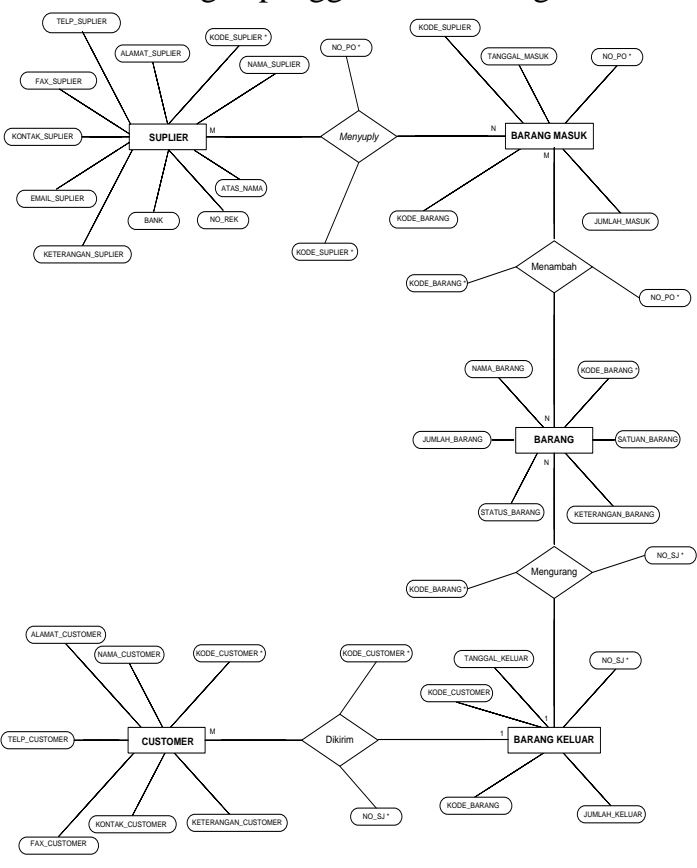

Gambar 3: Rancangan ERD 
Semua barang yang masuk dan keluar dicatat dan dikelolai tujuannya adalah untuk memudahkan pencarian informasi kedalam data inventory yang telah disediakan oleh sistem informasi. Proses perekaman data mengikuti aturan dan pola yang telah disepakati.

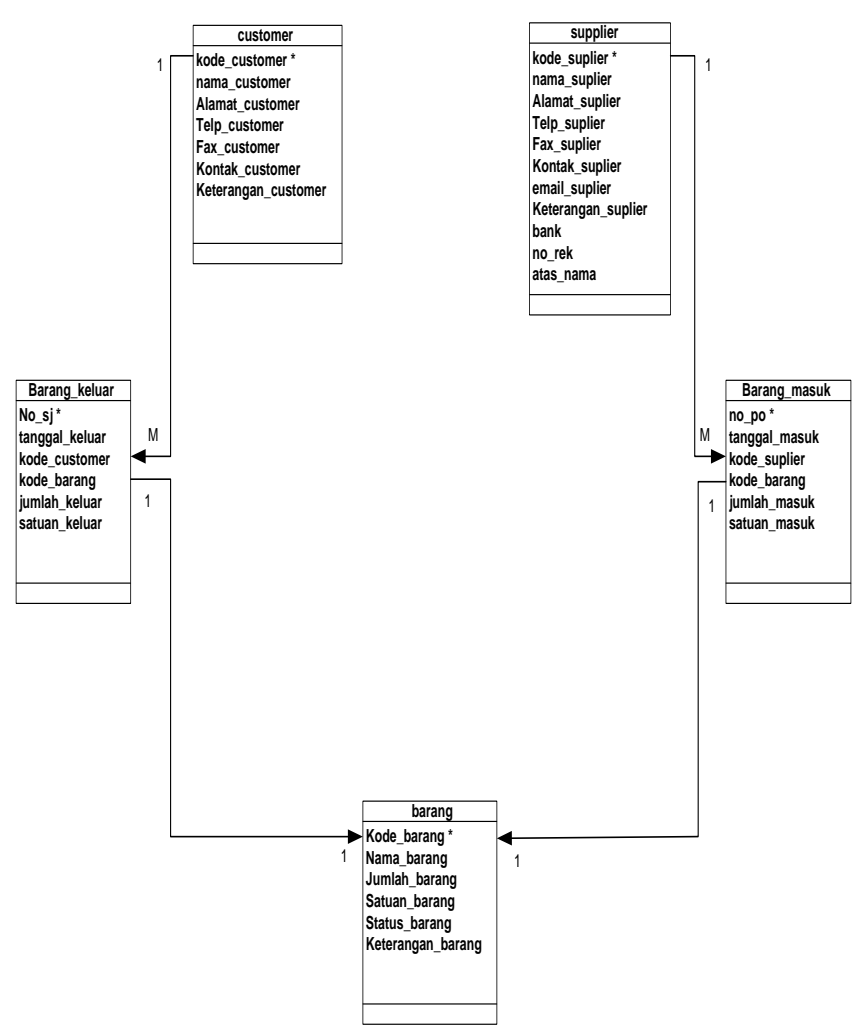

Gambar 4 : Rancangan LRS

\subsection{Proses Modeling}

Dalam proses modeling dengan Unified Modeling Language (UML)

Pemodelan mengunakan UML dapat memberikan gambaran sistem yang penulis bahas yaitu barang yang diterima oleh administrasi gudang akan disortir terlebih dahulu untuk mengetahui jenis/kelompok barang, selelah proses sortir surat akan disimpan pada rak-rak yang ada digudang sesuai dengan jenisnya. Serta administrasi mengarsipkan dokumen yang diterima dari supplier. Sedangkan untuk barang keluar, administrasi menerima permohonan dari bagian, setelah dilakukan pengecekan pada stok persetujuan kirim barang akan dikeluarkan, dan administrasi mengarsipkan bukti permohonan barang. Metode ini juga bertujuan menyatukan teknik pemodelan berorientasi objek yang terstandarisasi.

Sistem informasi warehouse adalah dimulai dari penerimaan barang dari supplier diterima dan dicatat oleh admin untuk disortir berdasarkan jenis/kelompok barang. Begitupun dengan barang yang keluar akan dicatat oleh admin berdasarkan permohonan yang masuk.

\subsection{Requirement}

Pengambaran kebutuhan dari sebuah sistem mengunakan use case diagram menggambarkan manfaat sistem jika dilihat dari sudut pandangan penguna yang berada diluar sistem ( actor ). Diagram ini menjelaskan fungsi suatu sistem atau kelas dan bagian yang berinteraksi dengan dunia luar.

Komponen pembentuk diagram use case adalah:

a. Aktor menggambarkan pihak-pihak yang berperan.

b. Use Case aktifitas atau sarana yang disiapkan oleh bisnis. Link actor yang terlibat,

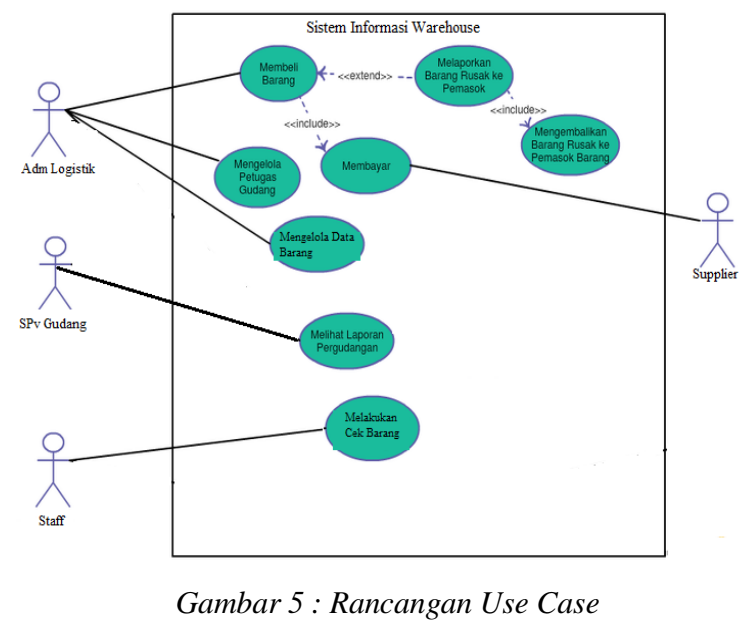

\section{Implementasi dan Pengujian}

Implementasi rancangan dalam tampilan interface masukkan, rancangan ini dimaksudkan untuk memudahkan administrasi gudang mengelola data gudang

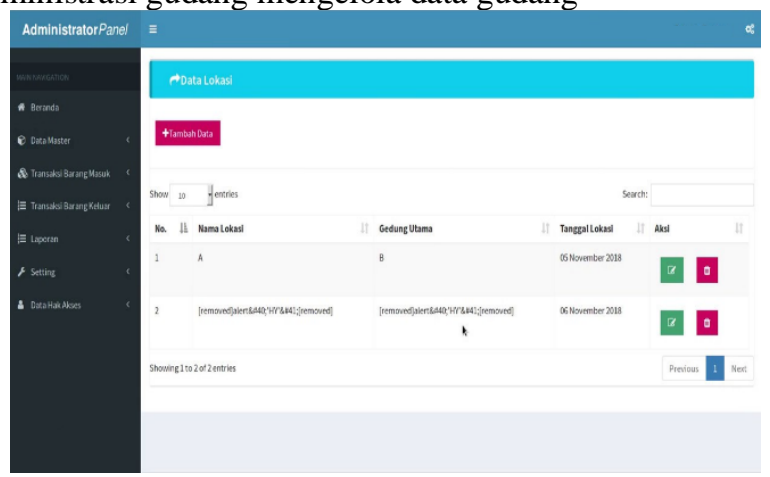

Gambar 6 : Rancangan Tampilan Administrasi Gudang. 
Pengujian

\begin{tabular}{|c|c|c|c|c|c|}
\hline No & Skenario Pengujian & Test Case & $\begin{array}{l}\text { Hasil Yang } \\
\text { Diharapkan }\end{array}$ & Hasil Pengujian & Kesimpulan \\
\hline 1 & $\begin{array}{c}\text { Mengosongkan field } \\
\text { yang berada dihalaman } \\
\text { baru }\end{array}$ & $\begin{array}{l}\text { Semua field dan } \\
\text { semua teks box } \\
\text { kosong }\end{array}$ & $\begin{array}{c}\text { Sistem akan } \\
\text { menolak akses jika } \\
\text { tdk ada inputan }\end{array}$ & Sesuai harapan & valid \\
\hline 2 & $\begin{array}{l}\text { Hanya menginput } \\
\text { sebagian data }\end{array}$ & $\begin{array}{l}\text { Kode supplier } \\
\text { diinput KS.001 dan } \\
\text { nama barang } \\
\text { terminal sisanya } \\
\text { dikosongkan }\end{array}$ & $\begin{array}{c}\text { Sistem akan } \\
\text { menolak } \\
\text { dikarenakan masih } \\
\text { ada field yang } \\
\text { kosong }\end{array}$ & Sesuai harapan & valid \\
\hline 3 & $\begin{array}{c}\text { Mengisi semua field } \\
\text { yang ada }\end{array}$ & Semua field diisi & Sistem merespon & Sesuai harapan & valid \\
\hline
\end{tabular}

\section{Simpulan}

Pembahasan diatas menunjukan bahwa sebuah organisasi saat ini sudah sangat tidak layak mengunakan sistem manual dalam pengelolaan data gudang, diera revolusi industri 4.0 pengunaan sistem informasi dalam automatisasi kantor sangat dibutuhkan untuk mendukung pekerjaan yang dilakukan. Pengelolaan data dengan metode pencatatan biasa dan belum terolah secara maksimal terutama untuk, pencatatan dan pelaporan. Dengan solusi yang diusulkan adalah pengunaan system informasi agar dapat mengelola data gudang, baik barang masuk maupun barang keluar sehingga data tersebut dapat dicari kapan saja dengan cepat apabila diperlukan.

\section{Kepustakaan}

[1] D. Iryaning, "PERANCANGAN SISTEM INFORMASI INVENTORi GUDANG BERBASIS INTRANET,” pp. 147154, 2018.

[2] A. B. Fauzi, I. Bagus, and G. Dwidasmara, "Perancangan Dan Implementasi Warehouse Management System Di Pt. Pertamina Dppu Ngurah Rai," vol. 1, no. 2, pp. 48-53, 2012.

[3] R. A. Indiharto, A. M. Hilda, and A. Avorizano, "Perancangan Sistem Informasi Inventory Barang Berbasis Web pada Perusahaan Pergudangan," Peranc. Sist. Inf. Invent. Barang Berbas. Web pada Perusah. Pergudangan, vol. 1, no. 1, pp. 38 48, 2016.

[4] F. R. Bella Syifa Fauziah, Gunawan Abdillah, "Perancangan dan Implementasi Warehouse... (Fauziah dkk.)," Peranc. Dan Implementasi Wareh. Manag. Sist. Pada Pt. Feed. Indones., pp. 146-151, 2013.

[5] D. Rahmayanti and R. Afrinando, "Perancangan Sistem Informasi pada Bagian Gudang PT. PN VI Unit Usaha Ophir," $J$. Optimasi Sist. Ind., vol. 12, no. 2, p. 420, 2016.

[6] S. Kosasi, "Penerapan Rapid Application Development Dalam Sistem Perniagaan Elektronik Furniture," Creat. Inf. Technol. J., vol. 2, no. 4, pp. 265-276, 2015.

[7] W. R. K, P. Juliana, and R. R. Pratama, "Perancangan Sistem Informasi Penjualan Menggunakan Metode Rapid Application Development ( Rad ) Di Pabrik Genteng Uun Super Jatiwangi," 2018.

[8] S. Aswati and Y. Siagian, "Model Rapid Application Development," Sesindo, pp. 317-324, 2016.
I. Elyana, I. Kholil, F. E. Schaduw, and A. Bisnis, "Rancang Bangun Sistem Informasi Manajemen Disposisi Surat Menyurat Dengan Menggunakan Model Rad ( Rapid Application Development )," vol. 1, no. 2, pp. 0-5, 2019. 